\title{
cAMP-Dependent Long-Term Potentiation of Nitric Oxide Release from Cerebellar Parallel Fibers in Rats
}

\author{
Shinji Kimura, ${ }^{1,2}$ Seiji Uchiyama, ${ }^{2}$ Hideaki E. Takahashi,, ${ }^{2}$ and Katsuei Shibuki ${ }^{1}$ \\ ${ }^{1}$ Department of Neurophysiology, Brain Research Institute, and '2Department of Orthopedic Surgery, School of Medicine, \\ Niigata University, Niigata 951-8585, Japan
}

\begin{abstract}
Nitric Oxide (NO) is released from parallel fibers (PFs) after PF stimulation. NO-cGMP signaling is essential for long-term depression (LTD) in cerebellar PF-Purkinje cell synapses, which also exhibit presynaptic long-term potentiation (LTP) after tetanic PF stimulation. This LTP is dependent on CAMP but not NO-cGMP signaling. In this study, we analyzed long-term changes of NO release from PFs in rat cerebellar slices using electrochemical NO probes. Repetitive PF stimulation at $10 \mathrm{~Hz}$ for $2 \mathrm{sec}$ elicited a transient increase in NO concentration $(2.2 \pm$ $0.1 \mathrm{nM} ;$ mean $\pm \mathrm{SEM} ; n=116)$. This NO release exhibited long-term potentiation $\left(\right.$ LTP $\left._{\mathrm{NO}}\right)$ by $36 \pm 3 \%(n=15)$ after tetanic PF stimulation. Induction of LTP $_{\text {NO }}$ was not affected by Glu receptor antagonists. NO release from PFs was also potentiated by L-Arg (ARG) $(100 \mu \mathrm{M})$, forskolin $(50 \mu \mathrm{M})$, and 8-bromo-cAMP (Br-cAMP) (1 $\mathrm{mm}$ ) but not by 1,9dideoxyforskolin $(50 \mu \mathrm{M})$, a biologically inactive analog of fors-
\end{abstract}

Nitric oxide (NO) has various biological functions (Bredt and Snyder, 1994). Induction of long-term potentiation (LTP) in the hippocampal area CA1 is facilitated by NO (Böhme et al., 1991; Schuman and Madison, 1991; Arancio et al., 1996; Son et al., 1996), although the NO dependence is affected by various experimental conditions, such as temperature or animal age (Williams et al., 1993). Induction of LTP in layer II/III in the visual cortex does not depend on NO signaling (Kirkwood and Bear, 1994), whereas induction of LTP in layer V of the medial frontal cortex does (Nowicky and Bindman, 1993). Cerebellar long-term depression (LTD) in parallel fiber (PF)-Purkinje cell synapses is also dependent on NO-cGMP signaling for the induction (Crepel and Jaillard, 1990; Ito and Karachot, 1990; Shibuki and Okada, 1991; Daniel et al., 1993; Lev-Ram et al., 1995; Hartell, 1996a), whereas NO does not affect LTD of Glu-induced currents in cultured Purkinje cells (Linden et al., 1995) or LTD elicited by strong PF stimulation (Hartell, 1996b). Certain types of cerebellar motor learning, for which LTD is regarded as the cellular mechanism (Ito, 1989), are also dependent on NO signaling (Nagao and Ito, 1991; Li et al., 1995; Yanagihara and Kondo, 1996). These studies strongly suggest that NO is a modulator of synaptic plasticity.

Received Feb. 2, 1998; revised Aug. 3, 1998; accepted Aug. 10, 1998.

This work was supported by grants from the Japanese Government, Toyota RIKEN, and the Uehara Foundation. We thank Y. Tamura and N. Taga for technical assistance.

Correspondence should be addressed to K. Shibuki, Department of Neurophysiology, Brain Research Institute, Niigata University, 1 Asahi-machi, Niigata 9518585, Japan.

Copyright (C) 1998 Society for Neuroscience $\quad 0270-6474 / 98 / 188551-08 \$ 05.00 / 0$ kolin. The potentiation induced by forskolin was significantly suppressed by H89 (10 $\mu \mathrm{M})$, a blocker of cAMP-dependent protein kinase. The potentiation induced by forskolin, but not that induced by Arg, interfered with LTP $_{\text {NO. }}$ H89 (10 $\left.\mu \mathrm{M}\right)$ and KT5720 (1 $\mu \mathrm{M})$, another blocker of cAMP-dependent protein kinase, but not KT5823 (300 nM), a blocker of cGMP-dependent protein kinase, significantly suppressed LTP NO. These data indicate that neural NO release is under activity-dependent control, just as synaptic transmitter release is. LTP $_{\text {NO }}$ might play a role in cross talk between presynaptic and postsynaptic plasticity by facilitating NO-cGMP-dependent postsynaptic LTD after induction of cAMP-dependent presynaptic LTP and LTP $_{\text {NO. }}$.

Key words: nitric oxide; cAMP; cGMP; long-term potentiation; cerebellum; parallel fiber

Of the isozymes of NO synthase (NOS), the neuronal type (nNOS) is widely distributed in the brain (Bredt et al., 1991). The nNOS activity is controlled by neural activities via $\mathrm{Ca}^{2+}-$ calmodulin (Bredt and Snyder, 1990). The nNOS molecule has several phosphorylation sites so that the function of nNOS may be modulated by phosphorylation (Brüne and Lapetina, 1991; Bredt et al., 1992). Although nNOS is a cytosolic enzyme, it has a high affinity for certain molecules, such as postsynaptic density proteins (Brenman et al., 1996a,b), and the intracellular distribution of nNOS may affect NO release. Activity-dependent changes in the distribution of nNOS immunoreactivity are found in the monkey visual cortex (Aoki et al., 1993). These data suggest the possibility that neural NO release may be under activitydependent control. In our previous study, a slight potentiation of NO release has been found after tetanic PF stimulation (Shibuki and Kimura, 1997). The purpose of this paper is to study activitydependent changes in NO release from PFs.

The mechanism of NO-cGMP-dependent LTD in PF-Purkinje cell synapses is explained by desensitization of postsynaptic Glu receptors (Ito et al., 1982; Linden et al., 1991; Nakazawa et al., 1995). Glu release from PFs, however, shows presynaptic LTP after tetanic PF stimulation (Salin et al., 1996; Linden, 1997), and this presynaptic LTP is dependent on cAMP but not cGMP (Salin et al., 1996). NO release in the molecular layer of the cerebellum is primarily derived from PFs, and the NO release is triggered by $\mathrm{Ca}^{2+}$ influx via voltage-gated $\mathrm{Ca}^{2+}$ channels (Shibuki and Kimura, 1997), just as Glu release from PFs is. Therefore, NO release from PFs may be modulated by cAMP. In this study, we investigate the roles of cyclic nucleotides in NO release from PFs. 


\section{MATERIALS AND METHODS}

Slice preparations. Slices of the cerebellar vermis were prepared from Wistar rats of either sex (4-7 weeks old). The rat, anesthetized with ether, was immersed in ice-cold water, except for the nose, for $3 \mathrm{~min}$ to reduce brain temperature. Immediately after decapitation, the brain was removed, and coronal slices $(400-\mu \mathrm{m}$-thick) of cerebellar vermis were prepared with a microslicer (DTK-2000; Dosaka, Osaka, Japan). The obtained slices were incubated in an artificial medium bubbled with $95 \%$ $\mathrm{O}_{2}$ and $5 \% \mathrm{CO}_{2}$. The composition of the medium was (in $\mathrm{mm}$ ): $\mathrm{NaCl} 124$, $\mathrm{KCl} 5, \mathrm{NaH}_{2} \mathrm{PO}_{4} 1.24, \mathrm{MgSO}_{4} 1.3, \mathrm{CaCl}_{2} 2.4, \mathrm{NaHCO}_{3} 26$, and glucose 10 , unless otherwise specified. When the $\mathrm{Ca}^{2+}$ concentration in the medium was changed, the sum of $\mathrm{MgSO}_{4}$ and $\mathrm{CaCl}_{2}$ concentrations was kept constant. After incubation at room temperature for more than $1 \mathrm{hr}$, the slices were transferred to a small recording chamber $(\sim 0.3 \mathrm{ml}$ in volume) in which the slices were kept submerged. The recording chamber was maintained at $30^{\circ} \mathrm{C}$ and was continuously perfused with the oxygenated medium at the flow rate of $1 \mathrm{ml} / \mathrm{min}$. The experiments were performed according to the guidelines of Niigata University and had been approved by the ethics committee of Niigata University.

Drugs. Forskolin was purchased from Wako Pure Chemical Industries (Osaka, Japan), and $N^{\mathrm{G}}$-nitro-L-arginine (NA) was purchased from Sigma (St. Louis, MO). 6-Cyano-7-nitroquinoxaline-2,3-dione (CNQX), D-2-amino-5-phosphonovalerate (APV), and (RS)- $\alpha$-methyl-4-carboxyphenylglycine (MCPG) were obtained from Tocris Cookson (Bristol, UK). H89 and KT5720 were obtained from Biomol Research Laboratory (Plymouth Meeting, MA), 1,9-dideoxyforskolin was from Research Biochemicals (Natick, USA), and KT5823 was from Kyowa Medex (Tokyo, Japan). These drugs were applied to the slices by adding into the perfusing medium.

NO probes. Electrochemical NO probes were fabricated as reported previously (Shibuki and Kimura, 1997). A glass pipette was obliquely polished such that the diameter of the tip was $\sim 250 \mu \mathrm{m}$. After the edge was smoothed by flaming, the pipette was filled with a solution containing $30 \mathrm{~mm} \mathrm{NaCl}$ and $0.3 \mathrm{~mm} \mathrm{HCl}$. The tip was sealed with a thin membrane of silicon rubber (TSE399; Toshiba). This membrane was prepared by placing a drop of TSE399 $(\sim 20-30 \mu \mathrm{l})$ on the surface of water. This drop spread over the surface of the water and polymerized within $50 \mathrm{~min}$. The glass pipette was inserted slowly into the water through the silicon rubber membrane so that the tip of the pipette was sealed with the silicon rubber membrane. The shank of the pipette was painted with a small amount of TSE399 to ensure electrical insulation. The pipettes were left for several hours to allow hardening of the silicon rubber. As a working electrode, Teflon-coated Pt wire (metal diameter, $125 \mu \mathrm{m}$ ) was used. The tip was cut obliquely and heated in the tip of the flame of an ethyl alcohol lamp for a few seconds to remove the Teflon coating. The Pt wire, except at the tip, was insulated with heat-melted dental wax. The Pt wire was inserted into the pipette. The tip was protruded from the pipette (see Fig. $2 A$ ). A reference (Teflon-coated $\mathrm{Ag}$ wire) was also inserted into the pipette and was connected to the ground. The working Pt wire was connected to a current-voltage converter. The anode voltage between the working Pt wire and the reference $\mathrm{Ag}$ wire was maintained at $+0.9 \mathrm{~V}$. Each NO probe was calibrated by measuring the probe currents in response to a 30 $\mu \mathrm{M}$ NO solution, which was prepared by dissolving $36 \mu \mathrm{l}$ of NO gas in 50 $\mathrm{ml}$ of degassed saline in a glass syringe. The sensitivity of the probes to $\mathrm{NO}$ was $0.2-1.1 \mathrm{nA} / \mu \mathrm{M} \mathrm{NO}$ at $30^{\circ} \mathrm{C}$ at the anode voltage of $+0.9 \mathrm{~V}$, and the $\mathrm{CO}$ sensitivity under this condition was $\sim 0.1 \%$ of the NO sensitivity. Usually, the NO probes could be used for more than a few weeks without significant changes in NO sensitivity.

Recording and stimulation. The PF volley potentials and field EPSPs elicited by PF stimulation were recorded extracellularly on the cut surface of the molecular layer in the slices through a glass micropipette filled with $2 \mathrm{M} \mathrm{NaCl}$. The field potentials were elicited by single pulse stimulation at $12 \mathrm{sec}$ intervals or by train pulse stimulation at $10 \mathrm{~Hz}$ for $2 \mathrm{sec}$. The five traces elicited by a single pulse or 20 traces elicited by 10 $\mathrm{Hz}$ train pulses were averaged to estimate the amplitude of the responses. The field EPSPs were isolated from the preceding PF volley potentials by subtracting the trace recorded in the presence of $10 \mu \mathrm{M} C N Q X$ from that recorded before CNQX application.

PFs were stimulated with biphasic pulses through the cut end of a Teflon-coated $\mathrm{Ag}$ wire placed on the surface of the slices. $\mathrm{AgCl}$ was deposited on the surface of the $\mathrm{Ag}$ wire by passing positive currents through the stimulating electrode in a $\mathrm{NaCl}$ solution. Every negative stimulus pulse was followed by a positive pulse, the absolute amplitude of which was $5 \%$ larger than that of the preceding negative pulse. Under these conditions, negative current from the stimulating electrode was

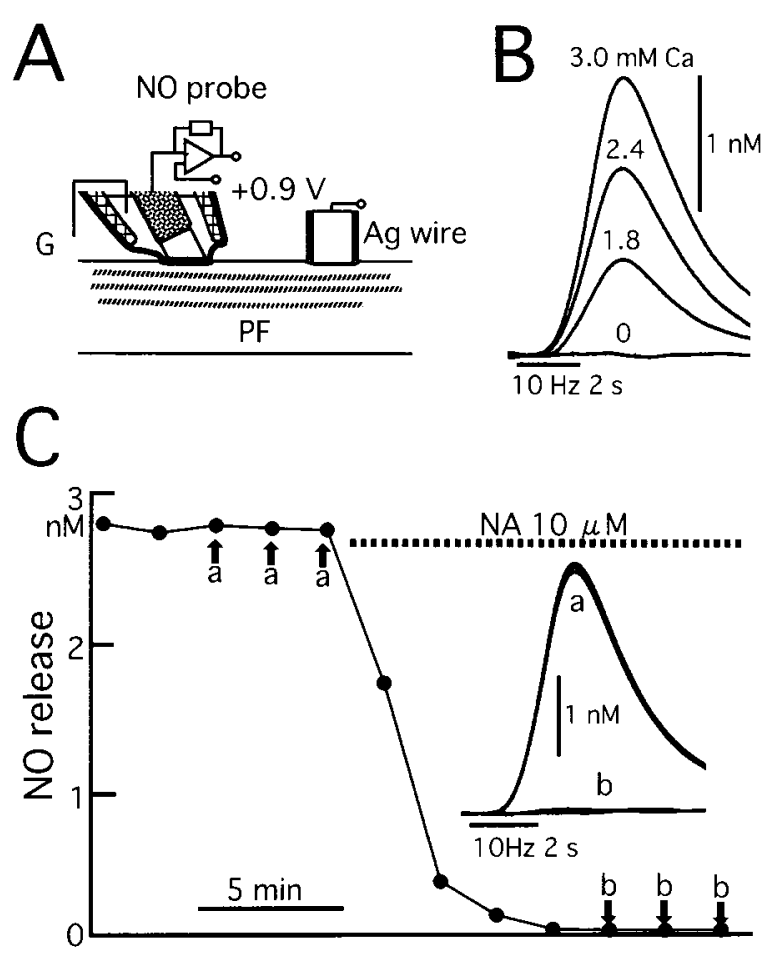

Figure 1. NO release from PFs in coronal cerebellar slices. $A$, Schema showing the experimental setup. $B$, NO release elicited by repetitive PF stimulation $(10 \mathrm{~Hz}$ for $2 \mathrm{sec})$ and recorded under different extracellular $\mathrm{Ca}^{2+}$ concentrations $(0-3.0 \mathrm{mM})$ in a slice. $C$, Amplitude of NO release elicited by repetitive PF stimulation at 2 min intervals and blockade of $\mathrm{NO}$ release by $10 \mu \mathrm{M}$ NA. Inset shows superimposed original traces recorded before $(a)$ and during $(b)$ NA application.

mediated by $\mathrm{Cl}^{-}$dissociated from $\mathrm{AgCl}$, and generation of $\mathrm{H}_{2}$ gas, which interfered with NO recording, was suppressed. The intensity of the negative stimulus pulse was $500 \mu \mathrm{A}$, unless otherwise specified. The duration of each pulse phase was $100 \mu \mathrm{sec}$. The tip of NO probe was placed on the surface of the molecular layer of cerebellar slices. The distance between the NO probe and the stimulating electrode was 100-200 $\mu \mathrm{m}$. Although NO release elicited by PF stimulation with single pulse is not detected with NO probes, the NO release exhibits marked frequency facilitation (Shibuki and Kimura, 1997). Therefore, we used PF stimulation with pulse trains at $10 \mathrm{~Hz}$ for $2 \mathrm{sec}$ for evoking NO release from PFs. The pulse trains were applied to slices at 2 min intervals. After the amplitude of NO release was stabilized, tetanic PF stimulation (TS) ( 5 pulses at $50 \mathrm{~Hz}$, repeated at $2 \mathrm{sec}$ intervals for $10 \mathrm{~min}$ ) was applied to the slices. Because mild TS was not sufficient to potentiate NO release after the NO release elicited by $10 \mathrm{~Hz}$ stimulation was stabilized, we chose this prolonged tetanus protocol. To estimate the effect of TS on NO release, the amplitude of NO release was normalized by the averaged value in three consecutive traces recorded immediately before TS. The amplitude of potentiation of NO release was evaluated at 30 min after TS. Statistical significance between the data were evaluated by the Mann-Whitney $U$ test, unless otherwise specified.

\section{RESULTS}

\section{NO recording in cerebellar slices}

NO release was recorded in the molecular layer of coronal cerebellar slices using an electrochemical NO probe placed on the surface of the molecular layer (Fig. $1 A$ ). Repetitive PF stimulation $(10 \mathrm{~Hz}$ for $2 \mathrm{sec})$ elicited a transient current increase in the NO probe (Fig. $1 B$ ). The current increase reached a peak between 3.0 and $4.2 \mathrm{sec}$ after initiation of the PF stimulation (peak amplitude latency), and the time period during which the current change exceeded half the amplitude of the peak (half amplitude duration) was between 3.1 and $4.3 \mathrm{sec}(n=116)$. We varied 
extracellular $\mathrm{Ca}^{2+}$ concentrations between 0 and $3.0 \mathrm{~mm}$. Amplitude of the current in the NO probe was positively correlated with extracellular $\mathrm{Ca}^{2+}$ concentration (Fig. 1B). The current increase, which corresponded to $0.7-4.6 \mathrm{~nm}$ NO $(2.2 \pm 0.1 \mathrm{nM}$; mean \pm SEM; $n=116$ ), was completely blocked by the addition of $10 \mu \mathrm{M}$ NA, a specific NOS blocker, into the medium perfusing the slice (Fig. $1 C$ ). These data indicate that NO release from PFs was reflected in the increase of current through the NO probe, as reported previously (Shibuki and Kimura, 1997).

\section{LTP of NO release from PFs}

NO release elicited by repetitive PF stimulation exhibits gradual potentiation for 30-50 min after initiation of NO recording (Shibuki and Kimura, 1997). In this study, we observed similar gradual potentiation after initiation of NO recording (Fig. $2 A$ ). TS (5 pulses at $50 \mathrm{~Hz}$, repeated at $2 \mathrm{sec}$ interval for $10 \mathrm{~min}$ ) was applied to the slices after the amplitude of NO release was stabilized. Potentiation of NO release was elicited by TS (Fig. $2 A$ ). The maximal amplitude of this potentiation $(67 \pm 7 \% ; n=15)$ was observed within a few minutes after cessation of TS. Subsequently, amplitude of NO release was gradually reduced. However, the potentiation lasted for $>30 \mathrm{~min}$ (Fig. $2 \mathrm{~B}$ ), and the amplitude of potentiation 30 min after cessation of TS was $36 \pm$ $3 \%(n=15)$. Neither the peak amplitude latency nor half amplitude duration was changed by TS (Fig. $2 A$, inset). In the absence of TS, no clear potentiation of NO release was observed (Fig. $2 B, a)$. PF volley potentials elicited by a single pulse $(n=5)$ (Fig. $2 B, b)$ or the averaged potentials of 20 traces elicited by PF stimulation at $10 \mathrm{~Hz}$ for $2 \mathrm{sec}(n=5)$ (Fig. $2 B, c)$ exhibited no potentiation after TS. These data strongly suggest that $\mathrm{LTP}_{\mathrm{NO}}$ was elicited by TS.

Presynaptic LTP of Glu release is also elicited by TS (Salin et al., 1996). Therefore, field EPSPs in Purkinje cells and NO release were simultaneously recorded at the both sides of single stimulating electrode in five slices (Fig. $2 C$, inset). During the initial $50 \mathrm{~min}$ of recording, NO release was gradually potentiated by $28 \pm 6 \%(n=5)$, whereas the averaged field EPSPs of 20 traces elicited by PF stimulation at $10 \mathrm{~Hz}$ for $2 \mathrm{sec}$ exhibited only modest potentiation ( $8 \pm 9 \% ; n=5$ ) (Fig. $2 C$ ). TS elicited $\mathrm{LTP}_{\mathrm{NO}}$ by $38 \pm 7 \%$ in the five slices, whereas no clear potentiation of the averaged field EPSPs were observed after TS (Fig. 2C). The difference in the TS-induced potentiation between NO release and averaged field EPSPs was significant $(p<0.05$; Wilcoxon signed rank test). Similar discrepancy between NO release and field EPSPs was also found in the experiments in which the stimulus intensity was decreased from 500 to $400 \mu \mathrm{A}(n=5)$, or the $\mathrm{Ca}^{2+}$ concentration in the perfusing medium was decreased from 2.4 to $1.8 \mathrm{~mm}(n=5)$ (Fig. $2 C)$. The reduction of NO release was significantly larger than that of the field EPSPs in these experiments $(p<0.05$ for both experiments; Wilcoxon signed rank test). These results strongly suggest that field EPSPs were saturated under the experimental conditions used for recording LTP $_{\text {NO }}$. Therefore, we reduced the intensity of PF stimulation from 500 to $50 \mu \mathrm{A}$ so that only field EPSPs were recorded clearly (data not shown). However, the field EPSPs elicited by test stimuli of $10 \mathrm{~Hz}$ for $2 \mathrm{sec}$ exhibited almost no change after TS at the stimulus intensity of $50 \mu \mathrm{A}$, and the amplitude of the averaged field EPSPs $30 \mathrm{~min}$ after cessation of TS was $99 \pm 3 \%(n=5)$ of that recorded immediately before TS.

In the molecular layer, PFs make synapses with neurons, among which basket neurons express nNOS (Bredt et al., 1991). To ascertain the possible contribution of postsynaptic neurons of PFs
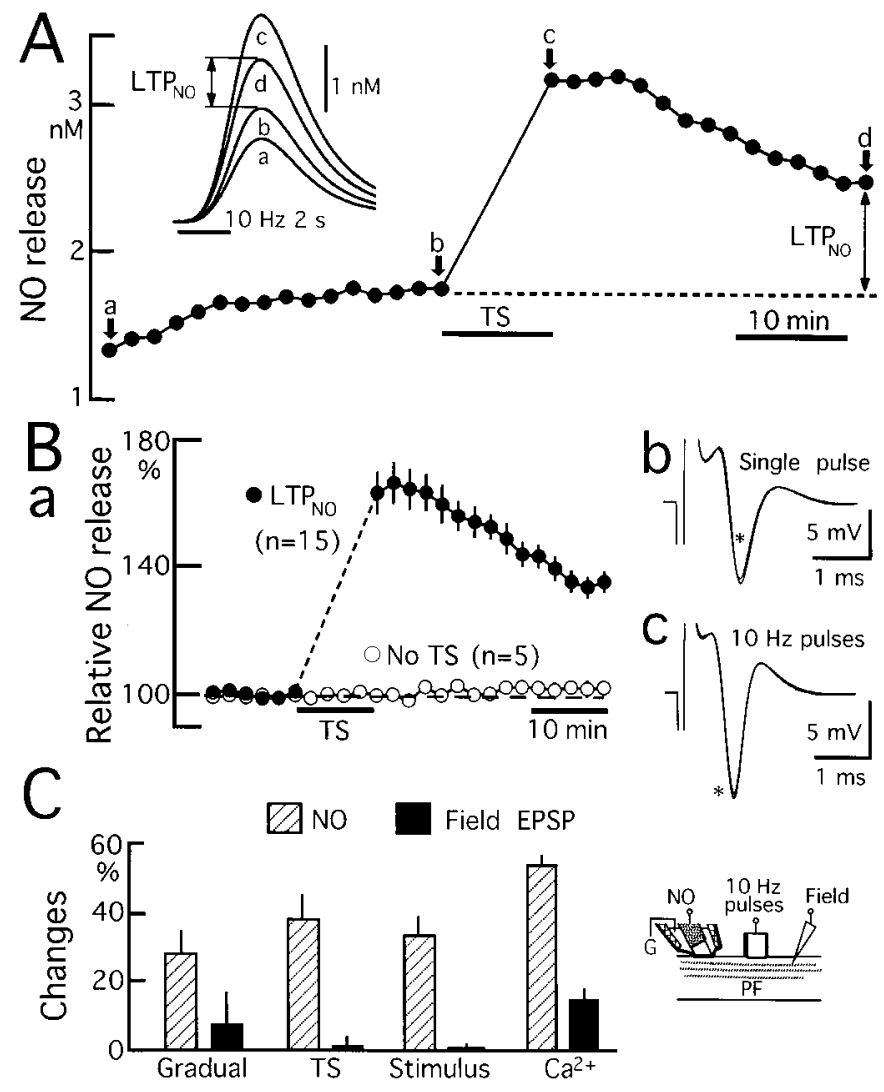

Figure 2. LTP $_{\text {NO }}$ elicited by TS. $A$, Amplitude of NO release recorded before and after TS. Inset shows superimposed traces of NO release recorded at the initiation of recording $(a)$, immediately before initiation of TS $(b)$, immediately after cessation of TS $(c)$, and $30 \mathrm{~min}$ after cessation of TS $(d) . B, a$, Time course of relative NO release before and after TS (filled circles) or in the absence of TS (open circles). B, $b$, Averaged PF volley potentials elicited by single pulse stimulation immediately before initiation and $30 \mathrm{~min}$ after cessation of TS (asterisk). B,c, Averaged PF volley potentials elicited by $10 \mathrm{~Hz}$ train pulses immediately before initiation and $30 \mathrm{~min}$ after cessation of TS (asterisk). $C$, Changes in NO release (hatched bars) and field EPSPs (filled bars). Gradual potentiation during the initial $50 \mathrm{~min}$ of the recording (Gradual), TS-induced potentiation $(T S)$, the reduction caused by the change in stimulus intensity from 500 to $400 \mu \mathrm{A}$ (Stimulus), and the reduction caused by the change in extracellular $\mathrm{Ca}^{2+}$ concentration from 2.4 to $1.8 \mathrm{mM}(\mathrm{Ca} 2+)$ are shown. The amplitude of each change was normalized by the amplitude of NO release or field EPSPs recorded before the change occurred. Each bar and error bar represent the absolute value of the mean \pm SEM of five experiments. Except for the experiment in which extracellular $\mathrm{Ca}^{2+}$ concentration was decreased, NO release and field EPSPs were simultaneously recorded in the same slice, as shown by the inset.

to $\mathrm{LTP}_{\mathrm{NO}}$, we applied CNQX $(10 \mu \mathrm{M})$, an antagonist of nonNMDA receptors. However, amplitude of NO release was not clearly affected by CNQX (Fig. $3 A$ ), suggesting that most of the $\mathrm{NO}$ was derived from PFs. Furthermore, $\mathrm{LTP}_{\mathrm{NO}}$ was elicited by TS in the presence of $10 \mu \mathrm{M}$ CNQX. Although LTP $_{\text {NO }}$ was slightly reduced in the presence of $10 \mu \mathrm{M} C \mathrm{CNX}$, no significant difference was found in the $\mathrm{LTP}_{\mathrm{NO}}$ amplitude elicited in the absence or presence of $10 \mu \mathrm{M}$ CNQX (Fig. 3D). We studied the contribution of other Glu receptors to the induction of $\mathrm{LTP}_{\mathrm{NO}}$. However, LTP $_{\mathrm{NO}}$ amplitude was significantly affected by neither APV $(50 \mu \mathrm{M})$, a blocker of NMDA receptors, nor MCPG (500 $\mu \mathrm{M}$ ), a blocker of metabotropic Glu receptors (Fig. $3 B-D$ ). Simultaneous application of CNQX and MCPG, both of which 

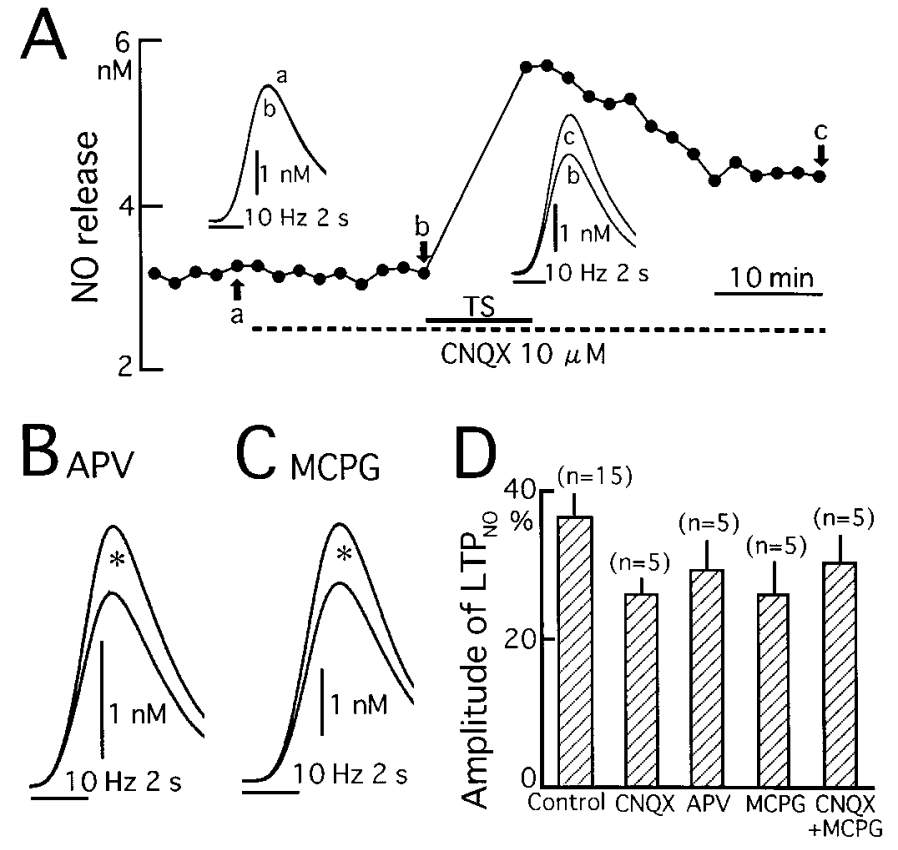

Figure 3. Effects of Glu blockers on $\mathrm{LTP}_{\mathrm{NO}} \cdot A$, Amplitude of NO release recorded before, during, and after application of CNQX $(10 \mu \mathrm{M})$ and TS. Insets show superimposed traces recorded immediately before application of CNQX $(a)$ or TS $(b)$ and $30 \mathrm{~min}$ after cessation of TS $(c) . B$, Superimposed traces recorded before and $30 \mathrm{~min}$ after TS (asterisk), which was applied to the slice in the presence of $50 \mu \mathrm{M}$ APV. C, Traces recorded before and $30 \mathrm{~min}$ after TS (asterisk) applied in the presence of $500 \mu \mathrm{M}$ MCPG. $D$, Amplitude of control $\mathrm{LTP}_{\mathrm{NO}}$ and $\mathrm{LTP}_{\mathrm{NO}}$ elicited in the presence of $10 \mu \mathrm{M}$ CNQX, $50 \mu \mathrm{M}$ APV, $500 \mu \mathrm{M} \mathrm{MCPG}$, or $10 \mu \mathrm{M}$ CNQX plus $500 \mu \mathrm{M}$ MCPG. The mean \pm SEM are shown.

block postsynaptic Glu receptors in Purkinje cells, was also ineffective (Fig. 3D).

$\mathrm{NO}$ is produced from L-arginine (Arg). NO release from PFs was augmented by the addition of Arg into the perfusing medium in a dose-dependent manner (Fig. $4 A$ ). The augmentation of the NO release by Arg reached a plateau at an Arg concentration of $100 \mu \mathrm{M}$ (Fig. 4A). Because this augmentation by $100 \mu \mathrm{M}$ Arg $(41 \pm 8 \% ; n=5)$ is comparable with the $\mathrm{LTP}_{\mathrm{NO}}$ amplitude, the mechanism of LTP $_{\text {NO }}$ might involve augmentation of Arg supply to PFs. To investigate this possibility, induction of $\mathrm{LTP}_{\mathrm{NO}}$ was tested in the presence of $100 \mu \mathrm{M}$ Arg (Fig. 4B,C). However, the LTP $_{\text {NO }}$ amplitude (35 $\left.\pm 4 \% ; n=5\right)$ was not significantly different from that in normal medium (Fig. 4C), suggesting that the mechanism of $\mathrm{LTP}_{\mathrm{NO}}$ probably does not involve augmentation of Arg supply to PFs.

\section{Dependence of the induction of LTP $_{\text {NO }}$ on CAMP}

Presynaptic LTP of Glu release from PFs is dependent on cAMP (Salin et al., 1996). Therefore, we studied the effect of forskolin, an activator of adenylate cyclase, on NO release from PFs. NO release exhibited potentiation after the addition of $50 \mu \mathrm{M}$ forskolin into the perfusing medium (Fig. $5 A$ ). Potentiation of NO release occurred gradually during forskolin application of $50 \mathrm{~min}$. The maximal amplitude of the potentiation was $62 \pm 17 \%(n=$ 7 ), which is comparable with the maximal amplitude of the potentiation elicited by TS. The forskolin-induced potentiation continued even after cessation of forskolin application, and the amplitude of the potentiation $30 \mathrm{~min}$ after cessation of forskolin application was $56 \pm 18 \%(n=7)$. The corresponding potentia-
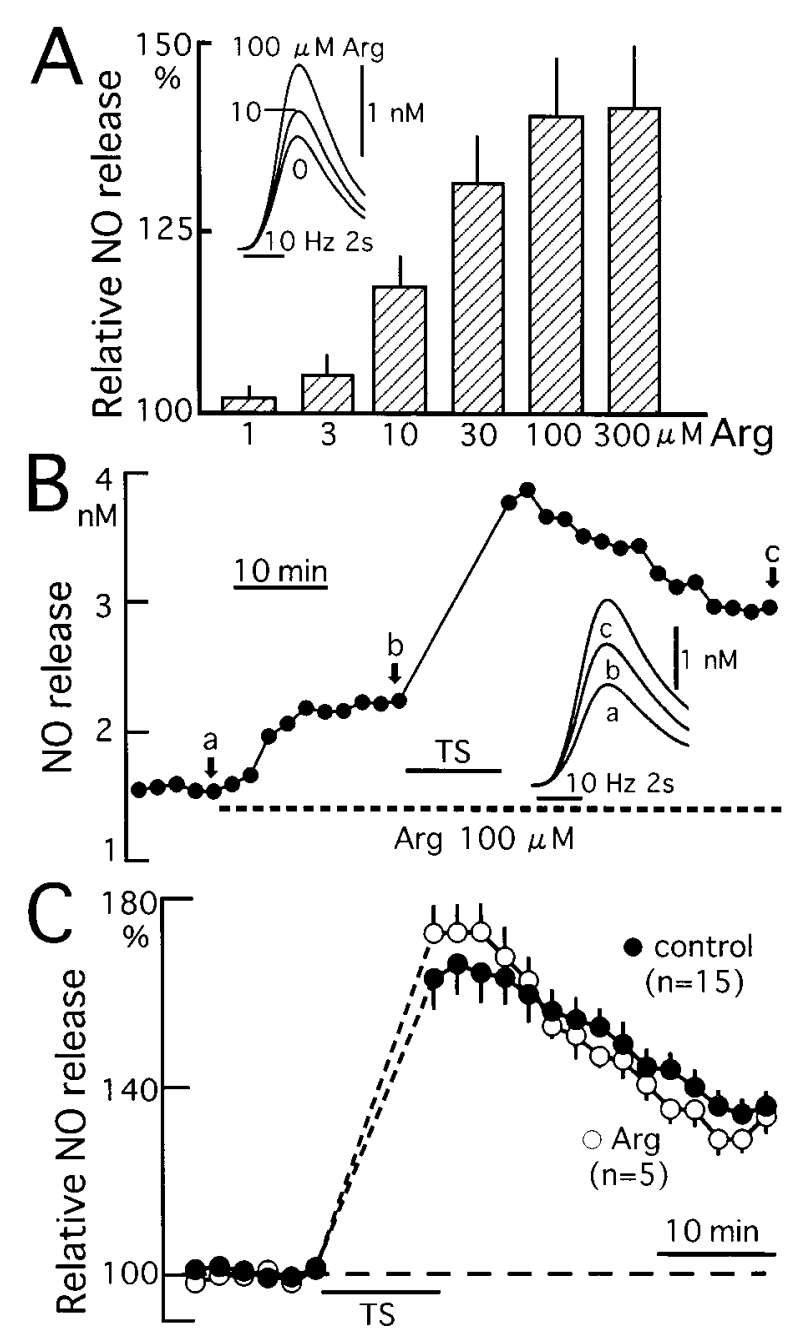

Figure 4. $\mathrm{LTP}_{\mathrm{NO}}$ in the presence of excessive Arg. $A$, Dependence of the amplitude of NO release on Arg concentration in the perfusing media. Data represent the mean \pm SEM of five experiments. The values are normalized by that recorded in the perfusing medium not containing Arg. Inset shows superimposed traces recorded in a slice in perfusing media containing 0-100 $\mu \mathrm{M}$ Arg. $B$, Changes in amplitude of NO release elicited by $100 \mu \mathrm{M}$ Arg application and TS. Inset shows superimposed traces recorded immediately before Arg application $(a)$, immediately before initiation $(b)$, and $30 \mathrm{~min}$ after cessation of TS $(c)$. $C$, Time courses of $\mathrm{LTP}_{\mathrm{NO}}$ in the presence (open circles) or absence of $100 \mu \mathrm{M}$ Arg (filled circles).

tion elicited by forskolin was $10 \pm 12 \%(n=5)$ in the presence of $10 \mu \mathrm{M}$ H89, a blocker of cAMP-dependent protein kinase, and this value was significantly smaller than that in normal medium $(p<0.05)$ (Fig. 5A). Furthermore, the amplitude of the potentiation observed $30 \mathrm{~min}$ after cessation of the application of 1,9-dideoxyforskolin (50 $\mu \mathrm{M}$ for $50 \mathrm{~min}$ ), a biologically inactive forskolin analog, was only $1 \pm 4 \%(n=5)$ (Fig. $5 B)$ and was significantly smaller than that observed after forskolin application $(p<0.001)$. These results strongly suggest that the forskolininduced potentiation of NO release is mediated by cAMP.

We speculated that forskolin-induced potentiation of $\mathrm{NO}$ release may share the mechanism with that of $\mathrm{LTP}_{\mathrm{NO}}$ elicited by TS. To investigate this possibility, TS was applied to the slices during forskolin application. However, TS elicited only transient potentiation of NO release (Fig. $5 B$ ), and the maximal amplitude of the potentiation elicited by TS during forskolin application 

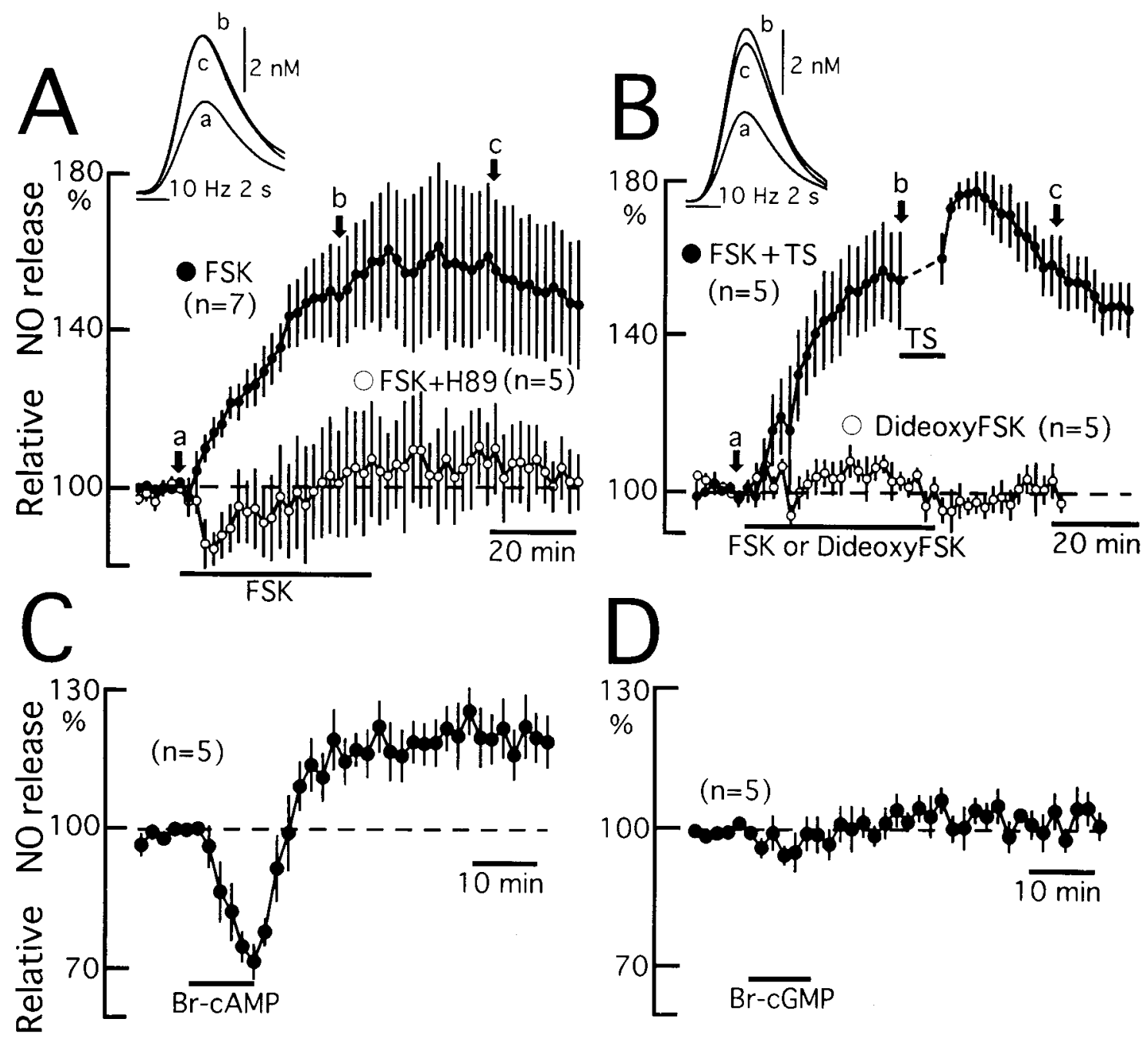

Figure 5. Potentiation of NO release induced by forskolin (FSK) and a cAMP analog. $A$, Potentiation of NO release induced by $50 \mu \mathrm{M}$ forskolin ( filled circles). Inset shows superposed traces recorded before application of forskolin $(a)$, in the presence of forskolin $(b)$, and 30 min after the cessation of forskolin application $(c)$. Forskolin-induced potentiation in the presence of $10 \mu \mathrm{M} \mathrm{H} 89$ is also shown (open circles). In this experiment, slices were incubated with $10 \mu \mathrm{M} \mathrm{H} 89$ for at least $2 \mathrm{hr}$ before and throughout the recording. B, Potentiation of NO release induced by forskolin and TS ( filled circles). Inset shows traces recorded before application of forskolin $(a)$, before initiation of TS $(b)$, and 30 min after the cessation of forskolin application and TS $(c)$. Changes in NO release elicited by application of 1,9-dideoxyforskolin $(50 \mu \mathrm{M}$, DideoxyFSK) are also shown (open circles). $C$, Potentiation of NO release induced by $1 \mathrm{~mm}$ Br-cAMP (horizontal bar). D, Effect of $1 \mathrm{~mm}$ Br-cGMP (horizontal bar) on NO release.

$(78 \pm 5 \% ; n=5)$ was comparable with that elicited by TS alone $(67 \pm 7 \% ; n=15)$. Furthermore, the amplitude of the potentiation $30 \mathrm{~min}$ after cessation of forskolin application and TS together $(57 \pm 9 \% ; n=5)$ was not significantly different from the amplitude of the potentiation elicited by forskolin alone (56 \pm $18 \% ; n=7)$. These findings are well explained if forskolininduced potentiation and TS-induced $\mathrm{LTP}_{\mathrm{NO}}$ share the same molecular mechanism.

To study the relationship between NO release and cAMP further, we applied 8-bromo-cAMP (Br-cAMP), a membranepermeable analog of cAMP, to the slices (Fig. $5 C$ ). During the application of $1 \mathrm{~mm} \mathrm{Br-cAMP}, \mathrm{NO}$ release was reduced by $28 \pm$ $4 \%(n=5)$. However, NO release recovered after washing out the $\mathrm{Br}-\mathrm{AMMP}$, and substantial potentiation of NO release $(19 \pm 5 \%)$ was observed $30 \mathrm{~min}$ after cessation of Br-cAMP application (Fig. $5 C$ ). In contrast, 8-bromo-cGMP (Br-cGMP) (1 mM), a membrane-permeable analog of cGMP, exhibited almost no effect on NO release (Fig. 5D), and there was a significant differ- ence in the amplitude of potentiation elicited by Br-cAMP and Br-cGMP $(p<0.03)$.

The facilitatory effect of cAMP on the induction of presynaptic LTP is blocked by H89 or KT5720, another blocker of A kinase A (Weisskopf et al., 1994; Salin et al., 1996). Therefore, we studied LTP $_{\text {NO }}$ in slices incubated with $10 \mu \mathrm{M}$ H89 or $1 \mu \mathrm{M}$ KT5720. Although TS elicited transient potentiation of NO release, amplitude of the potentiation $30 \mathrm{~min}$ after cessation of TS was $2 \pm 3 \%(n=5)$ in the presence of $10 \mu \mathrm{M} \mathrm{H} 89$ and $12 \pm 3 \%$ $(n=5)$ in the presence of $1 \mu \mathrm{M} \mathrm{KT5720} \mathrm{(Fig.} \mathrm{6A).} \mathrm{These} \mathrm{values}$ were significantly smaller than those recorded in slices incubated in normal medium ( $p<0.005$ for both data). As control, we studied LTP $_{\mathrm{NO}}$ in the slices incubated with $300 \mathrm{~nm} \mathrm{KT5823,} \mathrm{a}$ specific blocker of G kinase and NO-cGMP-dependent LTD (Ito and Karachot, 1992; Hartell, 1996a). However, no apparent effect of KT5823 on LTP $_{\text {NO }}$ was found (Fig. 6A). The amplitude of LTP $_{\mathrm{NO}}$ elicited by TS in the presence of KT5823 (36 $\pm 4 \% ; n=$ 5 ) was not significantly different from that of $\operatorname{LTP}_{\mathrm{NO}}$ elicited by 


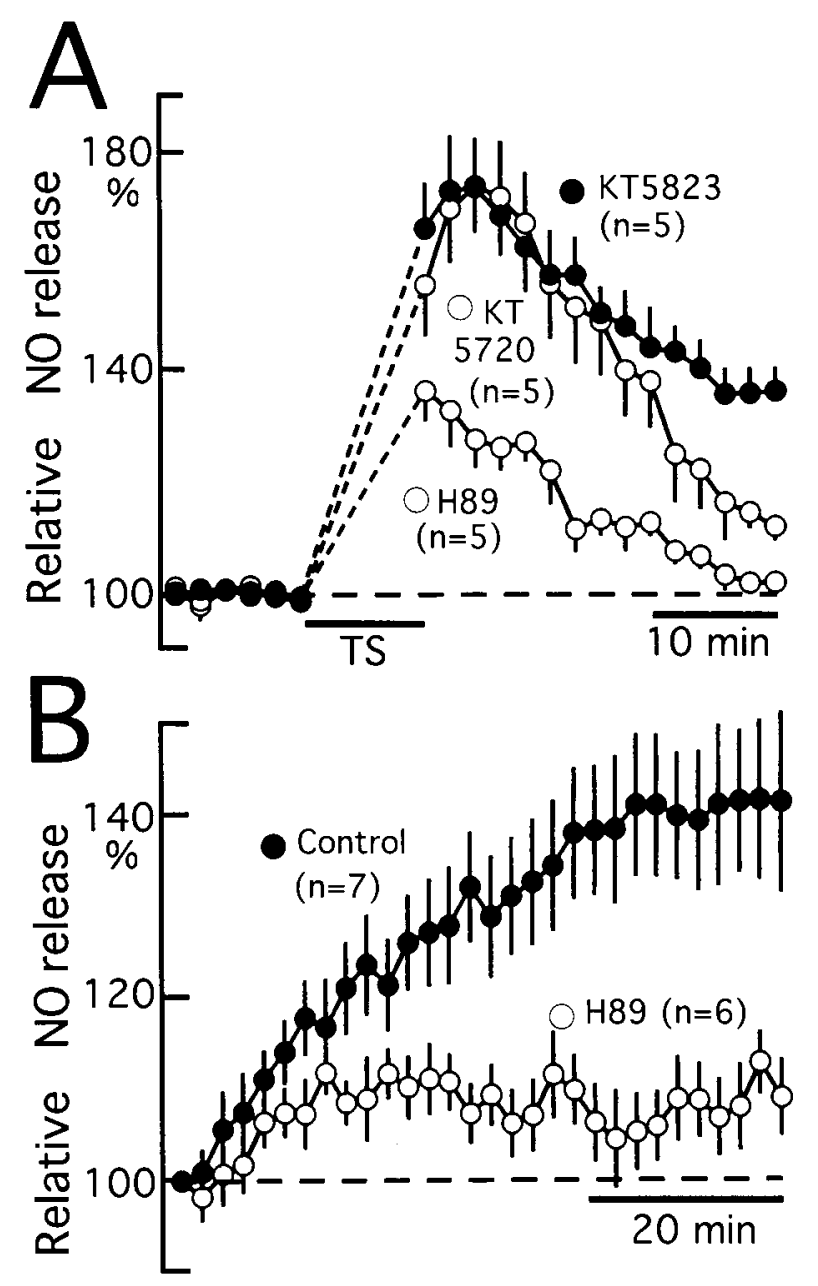

Figure 6. Blockade of $\mathrm{LTP}_{\mathrm{NO}}$ and gradual potentiation of $\mathrm{NO}$ release by $\mathrm{H} 89$ or KT5720. $A$, Time course of $\mathrm{LTP}_{\mathrm{NO}}$ recorded in the presence of 10 $\mu \mathrm{M}$ H89 (open circles), $1 \mu \mathrm{M}$ KT5720 (open circles), or 300 nM KT5823 (filled circles). B, Time courses of gradual potentiation of NO release induced by test stimuli in the absence (filled circles) or presence of $10 \mu \mathrm{M}$ H89 (open circles). Slices were incubated with $10 \mu \mathrm{M} \mathrm{H89,} 1 \mu \mathrm{M} \mathrm{KT5720,}$ or $300 \mathrm{nM} \mathrm{KT} 5823$ for at least $2 \mathrm{hr}$ before and throughout the recording.

TS in normal medium. These results, together with the data obtained from the forskolin and Br-cAMP experiments, indicate that $\mathrm{LTP}_{\mathrm{NO}}$ is dependent on cAMP but not on cGMP.

\section{Effect of $\mathrm{H} 89$ on the gradual potentiation of NO release}

NO release from PFs exhibits marked frequency facilitation (Shibuki and Kimura, 1997). In this study, we adopted PF stimulation of $10 \mathrm{~Hz}$ pulse trains to elicit clear NO release for quantitative analysis. Because repetitive PF stimulation at $8 \mathrm{~Hz}$ is sufficient to elicit LTP of Glu release from PFs (Salin et al., 1996), we expected that PF stimulation at $10 \mathrm{~Hz}$ may be sufficient to elicit potentiation of NO release from PFs. In accordance with this expectation, we observed the gradual potentiation during a period of 30-50 min after initiation of NO recording (Figs. 2A, 6B). We recorded the gradual potentiation in the slices incubated with $10 \mu \mathrm{M}$ H89 (Fig. 6B). The amplitude of the gradual potentiation during the initial $1 \mathrm{hr}$ of NO recording was $9 \pm 4 \%(n=6)$, and this value was significantly smaller than that recorded in normal medium $(43 \pm 10 \% ; n=7 ; p<0.02)$. This result suggests that repetitive $\mathrm{PF}$ stimulation at $10 \mathrm{~Hz}$ is sufficient to elicit potentiation of NO release in a cAMP-dependent manner.

\section{DISCUSSION \\ LTP of NO release from PFs}

In this study, we used an electrochemical NO probe whose tip was covered by a thin rubber membrane (Shibuki, 1990; Shibuki and Okada, 1991; Shibuki and Kimura, 1997). Because neither current nor electrolytes are released from the tip of the probe to the surrounding space, NO recording using this NO probe is suitable for detecting long-term changes in NO release without damaging tissue. In our previous study, we detected NO release from PFs elicited by PF stimulation using this probe (Shibuki and Kimura, 1997). The release of NO was identified by the characteristic dependency of the responses on the anode voltage in the probe and the sensitivity to NA. Furthermore, we found that NO release from PFs elicited by $20 \mathrm{~Hz}$ PF stimulation was slightly potentiated after TS (Shibuki and Kimura, 1997). However, the amplitude of the potentiation 30 min after cessation of TS was only $\sim 10 \%$, and therefore further analysis was not practicable. In this study, we adopted $10 \mathrm{~Hz}$ PF stimulation as test stimuli, and the amplitude of potentiation $30 \mathrm{~min}$ after cessation of TS was increased to $36 \pm$ $3 \%(n=15)$. This potentiation is not attributed to changes in the sensitivity of the NO probe, which usually showed stability for more than a few weeks. The probe currents elicited by PF stimulation were completely blocked by $10 \mu \mathrm{M}$ NA, even after TS (data not shown), and therefore the changes in the probe current must reflect net changes in NO concentration. Suppression of degradation of NO is unlikely to be caused by TS, because the time course of the probe currents was not changed by TS (Fig. $2 A$, inset). No clear potentiation of NO release was observed in the absence of TS (Fig. 2B,a). Amplitude of PF volley potentials was not potentiated by TS (Fig. $2 B, b$ ), and therefore changes in tissue excitability cannot explain the potentiation of the probe current. From these results, it is concluded that LTP $_{\mathrm{NO}}$ is elicited by TS in cerebellar slices.

\section{Comparison between LTP $_{\text {No }}$ and cAMP-dependent presynaptic LTP}

Although NO release is not dependent on exocytosis, $\mathrm{Ca}^{2+}$ influx via voltage-gated $\mathrm{Ca}^{2+}$ channels triggers not only Glu release but also NO release from PFs. Therefore, comparison of NO release and EPSPs in Purkinje cells may be of interest. The filed EPSPs simultaneously recorded with $\mathrm{LTP}_{\mathrm{NO}}$ exhibited no clear potentiation after TS. This result and the similar discrepancy regarding the dependency on extracellular $\mathrm{Ca}^{2+}$ concentration or stimulus intensity indicate that field EPSPs were saturated at the stimulus intensity of $500 \mu \mathrm{A}$, which was used for recording $\mathrm{LTP}_{\mathrm{NO}}$. The amplitude of PF volley potentials is almost linearly correlated to the stimulus intensity up to $500 \mu \mathrm{A}$ under our experimental conditions (Shibuki and Kimura, 1997). Therefore, the saturation of field EPSPs at $500 \mu \mathrm{A}$ cannot be attributable to saturated PF excitation but is probably explained by saturated postsynaptic depolarization. At the stimulus intensity of $50 \mu \mathrm{A}$, however, field EPSPs elicited by test stimuli of $10 \mathrm{~Hz}$ for $2 \mathrm{sec}$ exhibited almost no change after TS, suggesting that LTP $_{\text {NO }}$ and LTP of field EPSP may not necessarily occur in parallel.

In the hippocampus, there are two typical types of LTP (Bliss and Collingridge, 1993; Nicoll and Malenka, 1995). LTP in CA1 pyramidal neurons requires postsynaptic $\mathrm{Ca}^{2+}$ rise for the induction, whereas presynaptic LTP in mossy fiber-CA3 pyramidal neuron synapses does not require synaptic transmission and postsynaptic increase in $\mathrm{Ca}^{2+}$ concentration for the induction (Castillo et al., 1994; Weisskopf et al., 1994). Presynaptic LTP in sympathetic ganglion synapses (Kuba and Kumamoto, 1986), the 
mossy fiber synapses (Weisskopf et al., 1994), and cerebellar PF-Purkinje cell synapses (Salin et al., 1996) are dependent on cAMP for induction. LTP $_{\mathrm{NO}}$ was elicited in the presence of Glu receptor antagonists (Fig. 3) and is unlikely to be dependent on increase in $\mathrm{Ca}^{2+}$ concentration in postsynaptic neurons of PFs. The induction of $\mathrm{LTP}_{\mathrm{NO}}$ was dependent on cAMP and activation of kinase A (Figs. 5, 6). These characteristics of LTP $_{\mathrm{NO}}$ are similar to those of cAMP-dependent presynaptic LTP.

\section{Possible molecular mechanism for LTP $_{\text {NO }}$}

Electrical white matter stimulation causes an increase in the Arg level in rat cerebellar slices (Hansel et al., 1992). In the molecular layer, Arg is predominantly localized in Bergmann glial cells (Aoki et al., 1991). Glial synaptic currents exhibit LTP after repetitive stimulation of granule cells (Linden, 1997). Application of Arg to the slices potentiated NO release from PFs (Fig. 4A). Therefore, activity-dependent changes in Arg supply might be responsible for $\mathrm{LTP}_{\mathrm{NO}}$ elicited by TS. However, this hypothesis does not seem likely, because the amplitude of LTP $_{\mathrm{NO}}$ elicited in the presence of excess Arg was not significantly different from that of $\mathrm{LTP}_{\mathrm{NO}}$ elicited in normal medium (Fig. $4 C$ ). The primary structure of nNOS has several phosphorylation sites that are recognized by protein kinases (Bredt et al., 1992). However, activation of $\mathrm{A}$ or $\mathrm{C}$ kinases does not potentiate nNOS activity (Brüne and Lapetina, 1991; Bredt et al., 1992). Therefore, upregulation of Arg supply or potentiation of nNOS activity by phosphorylation does not seem to be responsible for the induction of $\mathrm{LTP}_{\mathrm{NO}}$ elicited by TS.

NO release from PFs is triggered by $\mathrm{Ca}^{2+}$ influx (Shibuki and Kimura, 1997), and NO release was positively correlated with extracellular $\mathrm{Ca}^{2+}$ concentration (Fig. 1B). Therefore, upregulation of $\mathrm{Ca}^{2+}$ influx is a possible mechanism for $\mathrm{LTP}_{\mathrm{NO}}$. Presynaptic LTP in the mossy fiber synapses interferes with paired pulse facilitation or frequency facilitation of synaptic transmission (Weisskopf et al., 1994). However, presynaptic LTP, but not paired pulse facilitation or frequency facilitation, is impaired in the Rab 3A deficient mice (Castillo et al., 1997). Rab 3A is a small G-protein involved in exocytosis of synaptic vesicles (Geppert et al., 1994, 1997). Therefore, changes in $\mathrm{Ca}^{2+}$ influx may not be responsible for cAMP-dependent presynaptic LTP, although $\mathrm{Ca}^{2+}$ influx is required for the induction (Castillo et al., 1994). Because NO release from PFs is also triggered by presynaptic $\mathrm{Ca}^{2+}$ influx (Shibuki and Kimura, 1997), changes in $\mathrm{Ca}^{2+}$ influx might not be responsible for $\mathrm{LTP}_{\mathrm{NO}}$.

Although nNOS is a cytosolic enzyme, it has affinity for specific molecules, such as postsynaptic density (PSD) proteins (Brenman et al., 1996a,b). In the monkey visual cortex, monocular deprivation elicits a decrease in nNOS immunoreactivity in the axon terminals in the corresponding cortical columns (Aoki et al., 1993). Because PSD proteins are also found in the cerebellum (Brenman et al., 1996a,b), distribution of nNOS molecules might be inhomogeneous in granule cells, and activity-dependent changes in nNOS distribution in granule cells might be elicited by TS. It has been proposed that exocytotic fusion is elicited by a very large and localized increase in $\mathrm{Ca}^{2+}$ concentration near the $\mathrm{Ca}^{2+}$ channels immediately after each action potential (Simon and Llinás, 1985). The NO release from PFs was sensitively dependent on extracellular $\mathrm{Ca}^{2+}$ concentration (Fig. $1 B$ ), and therefore even a slight change in the distribution of nNOS molecules with respect to the location of voltage-gated $\mathrm{Ca}^{2+}$ channels in PFs might be sufficient to modify NO release. However, no direct evidence supporting this presumption is available at present. Transmitter release is dependent on the complex mechanisms, including $\mathrm{Ca}^{2+}$-dependent exocytosis, whereas NO release from PFs is elicited simply by activation of nNOS via $\mathrm{Ca}^{2+}$-calmodulin. Therefore, understanding the mechanism for LTP $_{\text {NO }}$ might help the elucidation of the mechanism for presynaptic plasticity.

\section{Physiological roles of LTP $_{\text {NO }}$}

Although we used TS with $50 \mathrm{~Hz}$ pulses for induction of $\mathrm{LTP}_{\mathrm{NO}}$, gradual potentiation of $\mathrm{NO}$ release, which probably shares a molecular basis with $\mathrm{LTP}_{\mathrm{NO}}$, was elicited by $10 \mathrm{~Hz}$ PF stimulation. Because granule cells can fire at high frequency in vivo (Eccles et al., 1966), LTP $_{\mathrm{NO}}$ may be elicited in vivo. What is the physiological role of $\mathrm{LTP}_{\mathrm{NO}}$ in vivo? Cerebellar LTD in PFsPurkinje cell synapses is elicited by conjunctive stimulation of climbing fibers and PFs (Ito et al., 1982; Sakurai, 1987), and PF stimulation may be replaced with application of NO (Lev-Ram et al., 1995). This LTD is thought to reflect desensitization of postsynaptic Glu receptors (Ito et al., 1982; Linden et al., 1991; Nakazawa et al., 1995). LTP of PF-Purkinje cell synapses is also elicited by Br-cGMP when EGTA is injected into the Purkinje cells (Shibuki and Okada, 1992). Because soluble guanylate cyclase is localized in Purkinje cells (Ariano et al., 1982), this LTP might be of postsynaptic origin. Presynaptic LTD has been demonstrated in the mossy fiber synapses (Kobayashi et al., 1996; Yokoi et al., 1996). Because there is a similarity between presynaptic LTP in mossy fiber synapses and in PF-Purkinje cell synapses, PF-Purkinje cell synapses may also exhibit presynaptic LTD. Therefore, theoretically four types of synaptic plasticity can be present in PFs-Purkinje cell synapses. Plasticity of NO release might serve as a coordinator between presynaptic and postsynaptic plasticity in PF-Purkinje cell synapses. Changes in the ability to induce synaptic plasticity are known in various synapses, and these are referred to metaplasticity (Abraham and Bear, 1996). Dynamic changes in NO release could cause metaplasticity in synapses that exhibit NO-dependent synaptic plasticity.

\section{REFERENCES}

Abraham WC, Bear MF (1996) Metaplasticity: the plasticity of synaptic plasticity. Trends Neurosci 19:126-130.

Aoki C, Fenstemaker S, Lubin M, Go CG (1993) Nitric oxide synthase in the visual cortex of monocular monkeys as revealed by light and electron microscopic immunocytochemistry. Brain Res 620:97-113.

Aoki E, Semba R, Mikoshiba K, Kashiwamata S (1991) Predominant localization in glial cells of free L-arginine. Immunocytochemical evidence. Brain Res 547:190-192.

Arancio O, Kiebler M, Lee CJ, Lev-Ram V, Tsien RY, Kandel ER, Hawkins RD (1996) Nitric oxide acts directly in the presynaptic neuron to produce long-term potentiation in cultured hippocampal neurons. Cell 87:1025-1035.

Ariano MA, Lewicki JA, Brandwein HJ, Murad F (1982) Immunohistochemical localization of guanylate cyclase within neurons of rat brain. Proc Natl Acad Sci USA 79:1316-1320.

Bliss TV, Collingridge GL (1993) A synaptic model of memory: longterm potentiation in the hippocampus. Nature 361:31-39.

Böhme GA, Bon C, Stutzmann JM, Doble A, Blanchard JC (1991) Possible involvement of nitric oxide in long-term potentiation. Eur J Pharmacol 199:379-381.

Bredt DS, Snyder SH (1990) Isolation of nitric oxide synthetase, a calmodulin-requiring enzyme. Proc Natl Acad Sci USA 87:682-685.

Bredt DS, Snyder SH (1994) Nitric oxide: a physiologic messenger molecule. Annu Rev Biochem 63:175-195.

Bredt DS, Glatt CE, Hwang PM, Fotuhi M, Dawson TM, Snyder SH (1991) Nitric oxide synthase protein and mRNA are discretely localized in neuronal populations of the mammalian CNS together with NADPH diaphorase. Neuron 7:615-624.

Bredt DS, Ferris CD, Snyder SH (1992) Nitric oxide synthase regulatory 
sites. Phosphorylation by cyclic AMP-dependent protein kinase, protein kinase $\mathrm{C}$, and calcium/calmodulin protein kinase; identification of flavin and calmodulin binding sites. J Biol Chem 267:10976-10981.

Brenman JE, Christopherson KS, Craven SE, McGee AW, Bredt DS (1996a) Cloning and characterization of postsynaptic density 93, a nitric oxide synthase interacting protein. J Neurosci 16:7407-7415.

Brenman JE, Chao DS, Gee SH, McGee AW, Craven SE, Santillano DR, Wu Z, Huang F, Xia H, Peters MF, Froehner SC, Bredt DS (1996b) Interaction of nitric oxide synthase with the postsynaptic density protein PSD-95 and alpha1-syntrophin mediated by PDZ domains. Cell 84:757-767.

Brüne B, Lapetina EG (1991) Phosphorylation of nitric oxide synthase by protein kinase A. Biochem Biophys Res Commun 181:921-926.

Castillo PE, Weisskopf MG, Nicoll RA (1994) The role of Ca channels in hippocampal mossy fiber synaptic transmission and long-term potentiation. Neuron 12:261-269.

Castillo PE, Janz R, Südhof TC, Tzounopoulos T, Malenka RC, Nicoll RA (1997) Rab3A is essential for mossy fibre long-term potentiation in the hippocampus. Nature 388:590-593.

Crepel F, Jaillard D (1990) Protein kinases, nitric oxide and long-term depression of synapses in the cerebellum. NeuroReport 1:133-136.

Daniel H, Hemart N, Jaillard D, Crepel F (1993) Long-term depression requires nitric oxide and guanosine $3^{\prime}: 5^{\prime}$ cyclic monophosphate production in rat cerebellar Purkinje cells. Eur J Neurosci 5:1079-1082.

Eccles JC, Llinás RR, Sasaki K (1966) The mossy fibre-granule cell relay of the cerebellum and its inhibitory control by Golgi cells. Exp Brain Res 1:82-101.

Geppert M, Bolshakov VY, Siegelbaum SA, Takei K, Camilli PD, Hammer RE, Südhof TC (1994) The role of Rab3A in neurotransmitter release. Nature 369:493-497.

Geppert M, Goda Y, Stevens CF, Südhof TC (1997) The small GTPbinding protein Rab3A regulates a late step in synaptic vesicle fusion. Nature 387:810-814.

Hansel C, Batchelor A, Cuenod M, Garthwaite J, Knopfel T, Do KQ (1992) Delayed increase of extracellular arginine, the nitric oxide precursor, following electrical white matter stimulation in rat cerebellar slices. Neurosci Lett 142:211-214.

Hartell NA (1996a) Inhibition of cGMP breakdown promotes the induction of cerebellar long-term depression. J Neurosci 16:2881-2890.

Hartell NA (1996b) Strong activation of parallel fibers produces localized calcium transients and a form of LTD that spreads to distant synapses. Neuron 16:601-610.

Ito M (1989) Long-term depression. Annu Rev Neurosci 12:85-102.

Ito M, Karachot L (1990) Messengers mediating long-term desensitization in cerebellar Purkinje cells. NeuroReport 1:129-132.

Ito M, Karachot L (1992) Protein kinases and phosphatase inhibitors mediating long-term desensitization of glutamate receptors in cerebellar Purkinje cells. Neurosci Res 14:27-38.

Ito M, Sakurai M, Tongroach P (1982) Climbing fibre induced depression of both mossy fibre responsiveness and glutamate sensitivity of cerebellar Purkinje cells. J Physiol (Lond) 324:113-134.

Kirkwood A, Bear MF (1994) Hebbian synapses in visual cortex. J Neurosci 14:1634-1645.

Kobayashi K, Manabe T, Takahashi T (1996) Presynaptic long-term depression at the hippocampal mossy fiber-CA3 synapse. Science 273:648-650.

Kuba K, Kumamoto E (1986) Long-term potentiation of transmitter release induced by adrenaline in bull-frog sympathetic ganglia. J Physiol (Lond) 374:515-530.

Lev-Ram V, Makings LR, Keitz PF, Kao JPY, Tsien RY (1995) Longterm depression in cerebellar Purkinje neurons results from coincidence of nitric oxide and depolarization-induced $\mathrm{Ca}^{2+}$ transients. Neuron 15:407-415.
Li J, Smith SS, McElligott JG (1995) Cerebellar nitric oxide is necessary for vestibulo-ocular reflex adaptation, a sensorimotor model of learning. J Neurophysiol 74:489-494.

Linden DJ (1997) Long-term potentiation of glial synaptic currents in cerebellar culture. Neuron 18:983-994.

Linden DJ, Dickinson MH, Smeyne M, Connor JA (1991) A long-term depression of AMPA currents in cultured cerebellar Purkinje neurons. Neuron 7:81-89.

Linden DJ, Dawson TM, Dawson VL (1995) An evaluation of the nitric oxide/cGMP/cGMP-dependent protein kinase cascade in the induction of cerebellar long-term depression in culture. J Neurosci 15:5098-5105.

Nagao S, Ito M (1991) Subdural application of hemoglobin to the cerebellum blocks vestibuloocular reflex adaptation. NeuroReport 2:193-196.

Nakazawa K, Mikawa S, Hashikawa T, Ito M (1995) Transient and persistent phosphorylation of AMPA-type glutamate receptor subunits in cerebellar Purkinje cells. Neuron 15:697-709.

Nicoll RA, Malenka RC (1995) Contrasting properties of two forms of long-term potentiation in the hippocampus. Nature 377:115-118.

Nowicky AV, Bindman LJ (1993) The nitric oxide synthase inhibitor, $\mathrm{N}$-monomethyl-L-arginine blocks induction of a long-term potentiationlike phenomenon in rat medial frontal cortical neurons in vitro. J Neurophysiol 70:1255-1259.

Sakurai M (1987) Synaptic modification of parallel fibre-Purkinje cell transmission in in vitro guinea-pig cerebellar slices. J Physiol (Lond) 394:463-480.

Salin PA, Malenka RC, Nicoll RA (1996) Cyclic AMP mediates a presynaptic form of LTP at cerebellar parallel fiber synapses. Neuron 16:797-803

Schuman EM, Madison DV (1991) A requirement for the intercellular messenger nitric oxide in long-term potentiation. Science 254:1503-1506.

Shibuki K (1990) An electrochemical microprobe for detecting nitric oxide release in brain tissue. Neurosci Res 9:69-76.

Shibuki K, Kimura S (1997) Dynamic properties of nitric oxide release from parallel fibers in rat cerebellar slices. J Physiol (Lond) 498:443-452.

Shibuki K, Okada D (1991) Endogenous nitric oxide release required for long-term synaptic depression in the cerebellum. Nature 349:326-328.

Shibuki K, Okada D (1992) Cerebellar long-term potentiation under suppressed postsynaptic $\mathrm{Ca}^{2+}$ activity. NeuroReport 3:231-234.

Simon SM, Llinás RR (1985) Compartmentalization of the submembrane calcium activity during calcium influx and its significance in transmitter release. Biophys J 48:485-498.

Son H, Hawkins RD, Martin K, Kiebler M, Huang PL, Fishman MC, Kandel ER (1996) Long-term potentiation is reduced in mice that are doubly mutant in endothelial and neuronal nitric oxide synthase. Cell 87:1015-1023.

Weisskopf MG, Castillo PE, Zalutsky RA, Nicoll RA (1994) Mediation of hippocampal mossy fiber long-term potentiation by cyclic AMP. Science 265:1878-1882.

Williams JH, Li YG, Nayak A, Errington ML, Murphy KP, Bliss TVP (1993) The suppression of long-term potentiation in rat hippocampus by inhibitors of nitric oxide synthase is temperature and age dependent. Neuron 11:877-884.

Yanagihara D, Kondo I (1996) Nitric oxide plays a key role in adaptive control of locomotion in cat. Proc Natl Acad Sci USA 93:13292-13297.

Yokoi M, Kobayashi K, Manabe T, Takahashi T, Sakaguchi I, Katsuura G, Shigemoto R, Ohishi H, Nomura S, Nakamura K, Nakao K, Katsuki M, Nakanishi S (1996) Impairment of hippocampal mossy fiber LTD in mice lacking mGluR2. Science 273:645-647. 